\title{
Forensic Pharmacy: Some Risk Factors in the Formation of Addictive Health Disorders
}

\section{Viktoriya 0 Shapovalova ${ }^{1}$, Svitlana I Zbrozhek ${ }^{1}$, Valentyn V Shapovalov ${ }^{1,2 *}$, Valeriy V Shapovalov ${ }^{1}$}

${ }^{1}$ Medical and Pharmaceutical Law, General and Clinical Pharmacy Department, Kharkiv

Medical Academy of Postgraduate Education, Kharkiv, Ukraine

${ }^{2}$ Advocates Company "Apotheosis", Kharkiv, Ukraine

*Corresponding Author: Valentyn V Shapovalov, Medical and Pharmaceutical Law, General and Clinical Pharmacy Department, Kharkiv Medical Academy of

Postgraduate Education, Kharkiv, Ukraine.
Received: November 03, 2020

Published: December 22, 2020

(C) All rights are reserved by Valentyn $\mathbf{V}$

Shapovalov., et al.

\section{Abstract}

Presented correlation analysis of medical and social risk factors in the formation of addictive disorders in Ukraine. Established the probability that the indicators of social risk factors influence the indicators of medical risk factors in relation to the number of cases of diseases of the nervous system. The results obtained as a whole testify to the need for the further development of national programs for prevention of the development of addictive disorders due to the irrational use and abuse of psychoactive substances of different classification and legal groups. The following factors were found to be of the greatest importance: indicators of medical risk factors, which indicate the number of first reported cases of diseases and the number of cases of diseases of the nervous system; as well as a social risk factor for the circulation of psychoactive substances of different classification and legal groups.

Keywords: Pharmaceutical Law; Forensic Pharmacy; Addictive Disorders; Medical Risk Factors; Social Risk Factors; Circulation; Correlation

\section{Introduction}

Forensic and pharmaceutical researches on the uncontrolled circulation and irrational use of psychoactive substances of different classification and legal groups, the growth of offenses and crimes and the spread of addictive health disorders have become an independent direction in pharmacy with its methodology, research programs and schools, promising areas of research and established interdisciplinary links. Evolving, forensic pharmacy, both in application and conceptually, has constantly strengthened scientific ties with related sciences, including medical and pharmaceutical law, narcology, psychiatry, neurology, social medicine, forensic medicine, toxicology, social pharmacy, criminal, administrative law, which has made a significant theoretical and practi- cal contribution in the field of related knowledge and formed the interdisciplinary nature of forensic pharmacy. Medicinal, pharmacotherapeutic, prophylactic and preventive directions of forensic pharmacy are actively developed, the concept of causal relations at emergence, formation and distribution of addictive health disorders from psychoactive substances of various classification-legal groups is formulated, the basic organizational and legal, forensic and pharmaceutical approaches to the decision are defined problems of nervous diseases, alcohol, drug and drug addiction. However, despite the progress made, the issues of forensic pharmacy in the public consciousness are becoming increasingly scientific and practical relevance and social significance because of the aggravation of the situation with the circulation and abuse by psychoactive 
substances of various classification and legal groups in all countries, as evidenced by numerous organizational and legal, medical and social, forensic and pharmaceutical research. For example, the abuse by psychoactive substances in the form of alcoholic beverages at the regional level indicates an increase in cases of alcohol intoxication in adolescents, which has a detrimental effect on subsequent fertility and performance in this area [1-3]. Until now, forensic pharmaceutical studies of this problem have not been conducted in Ukraine.

The prevalence of addictive disorders in the world and in Ukraine is an acute medical, pharmaceutical and social problem. In the rating of mental illness in Ukraine, the first and second place is occupied by addictive disorders, the main reason for which is the irrational use and abuse of psychoactive substances. In Ukraine today $25-30 \%$ of cases of pediatric pathology of newborns are recorded and very often the reason is psychoactive substances. Almost $40 \%$ of Ukrainian adolescents between the ages of 14 and 18 consume alcoholic beverages regularly. Alcohol is the cause of premature death in almost $30 \%$ of Ukrainian men, with six drinking men accounting for one woman. The problem is actualized by the existing risk of infections, HIV/AIDS, the development of comorbid diseases (tuberculosis, hepatitis, oncology, panalgia, etc.), social consequences, deterioration of health of the most able-bodied part of the population and deepening of the general state of the population [4-6].

The above testifies to the relevance and timeliness of the study in the context of the relationship between medical and social risk factors in the formation of addictive disorders.

\section{Purpose of the Study}

The purpose of the work was to establish correlation between medical and social risk factors in the formation of addictive disorders, which determine the features of addictive disorders in Ukraine.

\section{Materials and Methods}

Statistical, correlation analysis methods were used to achieve this goal; statistical processing was performed using Statistica 6.0 program. The study uses data from the official Internet resources of Ukraine, which provide statistical indicators for 2014-2018 [7,8].

According to the purpose of the work, the design of the study was developed (Figure 1).

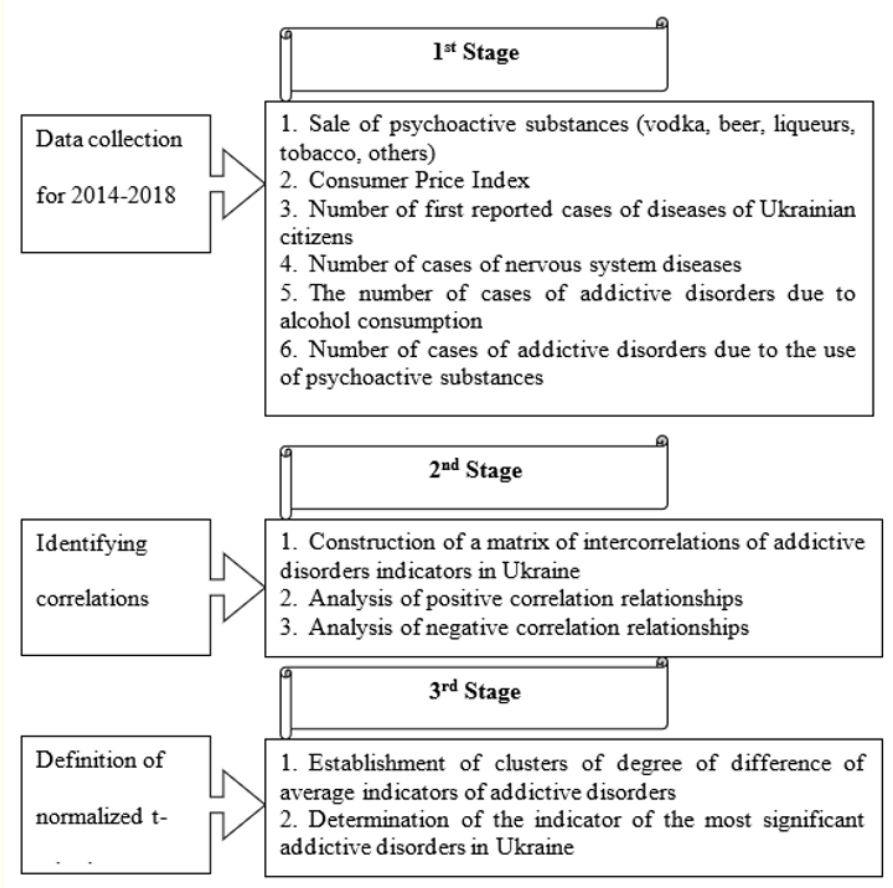

Figure 1: Design of the stages.

\section{Results and Discussion}

Correlation does not imply a causal relationship refers to the inability to legally derive causal relationships between two variables solely on the basis of the observed association or correlation between them. The idea that "correlation presupposes causation" is an example of a logical error that raises doubts in which two events occurring together are taken to establish causation. This error is also known by the Latin phrase cum hoc ergo propter hoc ("with this, therefore, because of this"). This is different from the error known as post hoc ergo propter hoc ("after that, therefore, because 
of this"), in which the event that follows another is considered a necessary consequence of the previous event $[9,10]$.

Like any logical error, finding that an argument is wrong does not necessarily mean that the conclusion is wrong. Methods that use correlation as a basis for testing causality hypotheses are proposed, including the Granger causality test and convergent crossmapping.

Causal analysis is an area of experimental design and statistics that deals with the establishment of causes and effects. For any two correlated events, A and B, their possible relationships include:

- $\quad$ A causes B (direct causal relationship);

- $\quad$ B causes A (causal feedback);

- $\quad$ A and B are both caused by C;

- A causes B, and B - A (bidirectional or cyclic causal relationship);

There is no connection between A and B; correlation - randomness.

Thus, it is not possible to infer the existence or direction of causation from the mere fact that A and B are related. Determining whether there is an actual causal relationship requires further investigation, even when the relationship between A and B is statistically significant, a large effect is observed, or a significant portion of the variance is explained. The opinion of the authors of the article was based on the fact that the causal link in the sense of law, in particular, criminal and medical and pharmaceutical - is an objective existing link between an act or phenomenon and subsequent consequences (sometimes - socially dangerous). It is also important to note that according to Brady, Henry E., the classic definition shared by Hume, John Stuart Mill, and many other scientists was that " $\mathrm{X}$ is the cause of $\mathrm{Y}$ if and only if $\mathrm{X}$ is sufficient for $\mathrm{Y}$ ". That is, the cause must always and invariably lead to the consequence. At the same time, the authors of the peer-reviewed article consciously understand that it is impossible to study and consider the whole set of socio-economic, medical and forensic pharmaceutical factors that affect the outcome in this work and requires further research and analysis. Relevant clarifications are made to the text of the article and highlighted in colour [10].
Correlation was established between two groups of risk factors in the formation of addictive disorders - medical and social $[11,12]$. Medical risk factors for the formation of addictive disorders were characterized by four indicators (Table 1): 1 - the number of first reported cases of diseases; 2 - the number of cases of diseases of the nervous system; 3 - the number of cases of addictive disorders due to alcohol; 4 - the number of cases of addictive disorders due to the use of psychoactive substances of different classification and legal groups (tobacco, alcohol, caffeine, sleeping pills, narcotics, psychotropic substances, precursors, etc.).

\begin{tabular}{|c|c|c|}
\hline No. & Indicator & Code \\
\hline & Number of first reported cases of diseases & Med.1 \\
\hline & $\begin{array}{c}\text { Number of cases of nervous system diseases } \\
\text { Number of cases of addictive disorders due } \\
\text { to alcohol consumption }\end{array}$ & Med. 3 \\
\hline & $\begin{array}{c}\text { Number of cases of addictive disorders due } \\
\text { to the use of psychoactive substances of dif- } \\
\text { ferent classification and legal groups }\end{array}$ & Med. 4 \\
\hline
\end{tabular}

Table 1: Indicators of medical risk factors in the formation of addictive disorders.

Social risk factors in the formation of addictive disorders included 5 indicators, which are presented in table 2 . The circulation of psychoactive substances means the stage of circulation - their sales. For the first time in previous studies, the authors proposed the classification and systematization of psychoactive substances by levels of ethanol strength (level I, ethanol from $0.5 \%$ to $12.0 \%$ - beer, soft drinks, energy drinks; energy drinks; level II, ethanol from $12.0 \%$ to $35.0 \%$ - wine, liqueurs, level III, ethanol from $35.0 \%$ and more - vodka, whiskey, rum), which is a scientific novelty, theoretical and practical significance.

\begin{tabular}{|c|c|c|}
\hline No. & Indicator & Code \\
\hline & Psychoactive substances circulation (beer) & Soc. 1 \\
\hline & Psychoactive substances circulation (liquors) & Soc. 2 \\
\hline & Psychoactive substances circulation (vodka) & Soc. 3 \\
\hline & $\begin{array}{c}\text { Circulation of psychoactive substances of dif- } \\
\text { ferent classification and legal groups }\end{array}$ & Soc. 5 \\
\hline
\end{tabular}

Table 2: Indicators of social risk factors in the formation of addictive disorders. 
Based on the collected data, a correlation analysis was conducted and a matrix of intercorrelations of risk indicators in the formation of addictive disorders in Ukraine was constructed (Table 3).

\begin{tabular}{|l|c|c|c|c|c|c|c|c|c|}
\hline & Soc. 1 & Soc. 2 & Soc. 3 & Soc. 4 & Soc. 5 & $\begin{array}{c}\text { Med. } \\
\mathbf{1}\end{array}$ & $\begin{array}{c}\text { Med. } \\
\mathbf{2}\end{array}$ & $\begin{array}{c}\text { Med. } \\
\mathbf{3}\end{array}$ & $\begin{array}{c}\text { Med. } \\
\mathbf{4}\end{array}$ \\
\hline Soc. 1 & 1,00 & 0,90 & 0,96 & $-0,39$ & $-0,49$ & 0,85 & 0,94 & $-0,01$ & $-0,98$ \\
\hline Soc. 2 & 0,90 & 1,00 & 0,93 & $-0,19$ & $-0,18$ & 0,60 & 0,75 & 0,25 & $-0,90$ \\
\hline Soc. 3 & 0,96 & 0,93 & 1,00 & $-0,51$ & $-0,52$ & 0,78 & 0,85 & 0,21 & $-0,99$ \\
\hline Soc. 4 & $-0,39$ & $-0,19$ & $-0,51$ & 1,00 & 0,94 & $-0,57$ & $-0,42$ & $-0,21$ & 0,50 \\
\hline Soc. 5 & $-0,49$ & $-0,18$ & $-0,52$ & 0,94 & 1,00 & $-0,65$ & $-0,52$ & $-0,08$ & 0,56 \\
\hline Med. 1 & 0,85 & 0,60 & 0,78 & $-0,57$ & $-0,65$ & 1,00 & 0,97 & $-0,39$ & $-0,78$ \\
\hline Med. 2 & 0,94 & 0,75 & 0,85 & $-0,42$ & $-0,52$ & 0,97 & 1,00 & $-0,32$ & $-0,86$ \\
\hline Med. 3 & $-0,01$ & 0,25 & 0,21 & $-0,21$ & $-0,08$ & $-0,39$ & $-0,32$ & 1,00 & $-0,19$ \\
\hline Med. 4 & $-0,98$ & $-0,90$ & $-0,99$ & 0,50 & 0,56 & $-0,78$ & $-0,86$ & $-0,19$ & 1,00 \\
\hline
\end{tabular}

Table 3: The matrix of intercorrelations between indicators of medical and social risk factors in the formation of addictive disorders in Ukraine.

To establish the reliability of correlation relationships, the reliability rating was divided into 4 criteria (Table 4 ).

\begin{tabular}{|c|c|c|}
\hline Criteria & Connection & Range \\
\hline & Missing & Under 0,54 \\
\hline & Minor & $0,55-0,65$ \\
\hline & Authentic & $0,66-0,74$ \\
\hline & Strong & $0,75-0,99$ \\
\hline
\end{tabular}

Table 4: Criteria for assessing of reliability.

According to the results of the analysis, the positive correlation (Figure 2) between the indicators were established that there is a high probability that: Med. 1 (number of first reported cases of diseases) and Med. 2 (number of cases of nervous system diseases); Med. 1 (number of first reported cases of diseases) and Soc. 1 (circulation of psychoactive substance beer); Med. 1 (number of first reported cases of diseases) and Soc. 3 (circulation of psychoactive substance vodka); Med. 2 (number of cases of nervous system diseases) and Soc. 1 (circulation of psychoactive substance beer); Med. 2 (number of cases of nervous system diseases) and Soc. 2 (circulation of psychoactive substance liquors); Med. 2 (number of cases of nervous system diseases) and Soc. 3 (circulation of psychoactive substance vodka); Soc. 1 (circulation of psychoactive substance beer) and Soc. 2 (circulation of psychoactive substance liquors); Soc. 1 (circulation of psychoactive substance beer) and Soc. 3 (circulation of psychoactive substance vodka); Soc. 2 (circulation of psychoactive substance liquors) and Soc. 3 (circulation of psychoactive substance vodka); Soc. 4 (consumer price index) and Soc. 5 (circulation of psychoactive substances of different classification and legal groups).

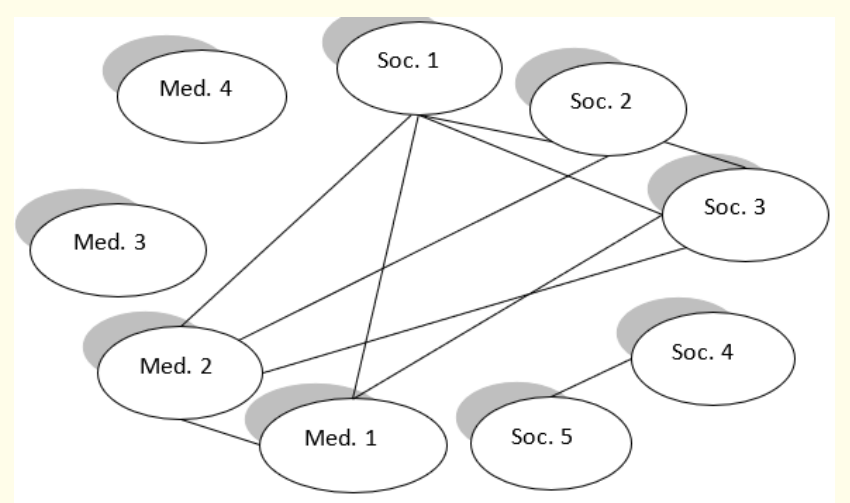

Figure 2: Positive correlation between medical and social risk factors in the formation of addictive disorders.

Negative correlation (Figure 3) was formed in Med. 4 (number of cases of addictive disorders due to the use of psychoactive substances) with indicators Soc. 1 (circulation of psychoactive substance beer), Soc. 2 (circulation of psychoactive substance liquors), Soc. 3 (circulation of psychoactive substance vodka), Med. 1 (number of first reported cases) and Med. 2 (number of cases of nervous system diseases).

According to the results of correlation analysis on the relationship between medical and social risk factors in the formation of addictive disorders in Ukraine, it is established that indicators of social risk factors (Soc. 1) affect the indicators of medical risk factors relative to the number of first reported cases of disease (Med. 1), 


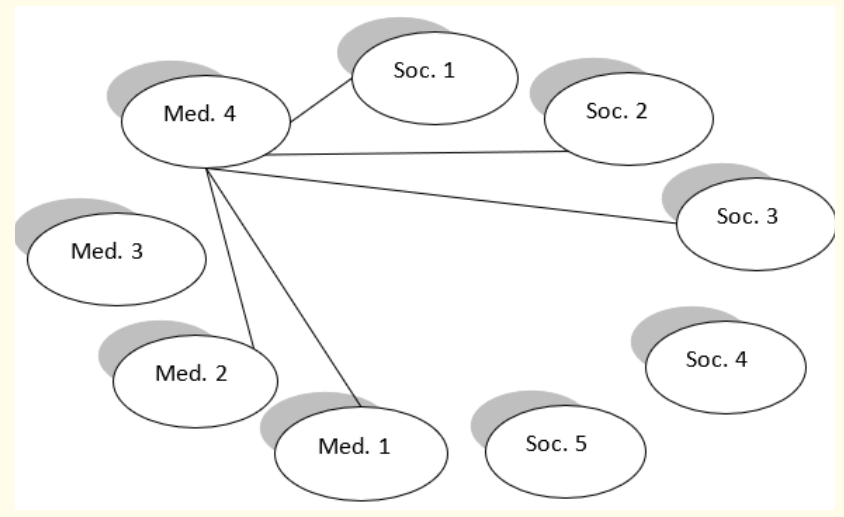

Figure 3: Negative correlation between medical and social risk factors in the formation of addictive disorders.

which generally indicates the need for the development of preventive measures aimed at improving the circulation of psychoactive substances that affect the formation of addictive disorders.

At the $3^{\text {rd }}$ stage of the study, the normalized t-criteria of medical and social risk factors was analyzed to determine the significance of each of the analyzed factors in the formation of addictive disorders in Ukraine. During the study of the degree of difference of averaged nine indicators of two risk factors, three clusters were allocated depending on the indicator of the t-criteria by the degree of difference (Figure 4).

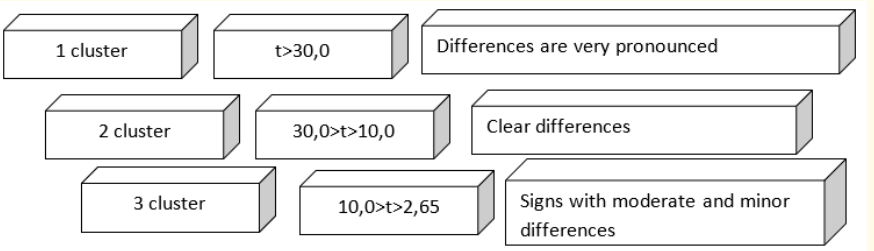

Figure 4: Clusters of degree of difference of averages.

The calculations of the normalized indicator of the t-criteria of medical and social risk factors in the formation of addictive disorders in Ukraine shown in table 5.

\begin{tabular}{|c|c|c|}
\hline No. & Cluster/Indicators & t-criteria \\
\hline \multicolumn{3}{|c|}{ 1 cluster } \\
\hline & Med. 2 & 55,680 \\
\hline & Med. 1 & 33,344 \\
\hline & 2 cluster \\
\hline & Soc. 5 & 27,781 \\
\hline & Soc. 4 & 14,333 \\
\hline & Soc. 1 & 11,402 \\
\hline & 3 cluster & 8,070 \\
\hline & Soc. 3 & 7,239 \\
\hline & Med. 3 & 7,097 \\
\hline & Soc. 2 & 5,093 \\
\hline
\end{tabular}

Table 5: Normalized indicator of $t$-criteria of medical and social risk factors in the formation of addictive disorders in Ukraine.

According to the results of the study, differences were found depending on the content of clusters of average indicators of addictive disorders of medical and social risk factors. One cluster with very marked differences is Med. 1 (number of first reported cases) and Med. 2 (the number of cases of nervous system diseases) that received the highest significance of the t-criteria (33.34 and 55.68 , respectively). The second cluster includes indicators of social risk factors in the formation of addictive disorders: Soc. 5 (circulation of psychoactive substances of different classification and legal groups) has a t-criteria indicator of 27.78; Soc. 4 (consumer price index - 14.33 and Soc. 1 (circulation of beer psychoactive substance) - 11,402. Cluster 3 includes indicators Soc. 3 (8,070); Med. 3 (7,239); Soc. 2 (7,097) and Med. 4 (5,093).

Thus, the structure of the normalized t-criterion of medical and social risk factors in the formation of addictive disorders in Ukraine is determined. It is established that indicators of medical risk factors, which indicate the number of first registered cases of diseases (Med. 1), the number of cases of diseases of the nervous system (Med. 2), as well as the indicator of social risk factors for the circulation of psychoactive substances of different classification and legal groups (Soc. 5), have the greatest importance for the formation of addictive disorders. 


\section{Conclusion}

The stages of the study are presented, the main ones being the collection of data for 2014-2018; identified a significant probability of correlative relationships determination of the normalized t-criteria which requires further study from the organizationallegal, socio-economic, medical and forensic-pharmaceutical side. It is indicated that the data processing was performed using Statistica 6.0.

Established that probably the indicators of social risk factors (Soc. 1 and Soc. 2) influence the indicators of medical risk factors in relation to the number of cases of diseases of the nervous system (Med. 2). The results obtained as a whole testify to the need for the development of national programs for prevention of the development of addictive disorders due to the irrational use and abuse of psychoactive substances of different classification and legal groups.

The structure of the normalized t-criteria of medical and social risk factors in the formation of addictive disorders in Ukraine is determined. The following factors were found to be of the greatest importance: indicators of medical risk factors, which indicate the number of first reported cases of diseases and the number of cases of diseases of the nervous system; as well as a social risk factor for the circulation of psychoactive substances of different classification and legal groups.

\section{Bibliography}

1. Shapovalova VO., et al. "Organizational and legal evaluation of availability of medicines' circulation for cancer patients". Pharmacia 65.2 (2018): 17-22.

2. Shapovalov (Jr.) ., et al. "Forensic and pharmaceutical analysis of addictive morbidity because of the use of narcotic psychoactive substances in Ukraine (retrospective aspect)". International Journal of Pharmaceutical Sciences and Research 3.3 (2018): 22-25.

3. V Shapovalov (Jr.)., et al. "Concerning the importance of forensic and pharmaceutical researches to improve patients' accessibility to medicines". Pharmacia 65.2 (2017): 23-29.
4. V Shapovalov (Jr.)., et al. "Forensic and pharmaceutical study of the presence of a causal link between the degree of alcohol abuse and qualification level of the respondents". Pharmacia 66.3 (2017): 31-39.

5. VA Shapovalova., et al. Legislation in pharmacy, forensic pharmacy and evidence-based pharmacy: Study book (series: Pharmaceutical law, 3rd ed.) Kharkiv, (2011): 160.

6. Shapovalov VV., et al. "The problem of turnover of the psychoactive substance alcohol: abuse, consequences, countermeasures". Research result (Medicine and Pharmacy Series) 1.2 (2014): 45-51.

7. Ministry of healthcare of Ukraine official site.

8. TV Kozhukhova., et al. "Basics of psycho-pedagogical research: teaching manual for scientific workers, students of higher education faculties of III-IV levels of accreditation". NPhAU, Kharkiv (2002): 240.

9. V Shapovalov (Jr.)., et al. "Organizational and legal analysis of the pharmaceutical provision for the most common diseases of society". International Journal of Pharmaceutical Sciences Review and Research 51.1 (2018): 118-124.

10. Brady Henry E. "Causation and Explanation in Social Science". The Oxford Handbook of Political Science (2011).

11. Shapovalov VV., et al. "Forensic and pharmaceutical analysis of addictive morbidity because of the use of psychotropic psychoactive substances in Ukraine (retrospective aspect)". Annals of Mechnikov Institute 3 (2018): 41-44.

12. V Shapovalov (jr.) ., et al. "Forensic and pharmaceutical assessment of polydrug addiction at combined use of psychoactive substances". Likarska sprava 1-2.1146 (2012): 171-177.

\section{Assets from publication with us}

- Prompt Acknowledgement after receiving the article

- Thorough Double blinded peer review

- Rapid Publication

- Issue of Publication Certificate

- High visibility of your Published work

Website: https://www.actascientific.com/

Submit Article: https://www.actascientific.com/submission.php

Email us: editor@actascientific.com

Contact us: +919182824667 